\title{
Application of Unified Power Quality Conditioner in Grid Integration of Solar PV System
}

\author{
Niaz Ali ${ }^{1}$, Prof. Dr. Muhammad Naeem Arbab ${ }^{2}$, Rizwan Kamal ${ }^{3}$, Muhammad Bilal $^{4}$ \\ 1,2,3,4 US Pakistan Center for Advanced Studies in Energy, University of Engineering and Technology, Peshawar \\ engr.niazi91@yahoo.com¹, mnarbab@yahoo.com², rkrizwan891@gmail.com ${ }^{3}$, engr.bila192@gmail.com ${ }^{4}$ \\ Received: 14 December, Revised: 20 December, Accepted: 27 December
}

\begin{abstract}
Modern power electronics has developed a great interest in grid integration of solar photovoltaics. The penetration of renewable energy resources causes problems of power quality, due to their intermittent behavior. These problems include but are not limited to reactive power flow, voltage dip or sag, over-voltage, distortions in current and voltage waveforms. Similarly, non-linear loads have been consistently increased on the consumer side. These power electronics-based equipment bring harmonics into the power system and as result demand of reactive power rises. This research aims a Unified Power Quality Conditioner for grid integration of solar PV. In the proposed technique, a part of the PV power is used for the power quality management and the rest of the power is sent back into the grid. The major constituents of PV system are; DC-DC boost converter, PV array, whereas, $\mathrm{P} \& \mathrm{O}$ algorithm is adopted to ensure the maximum power point operation of the PV array. The analysis and testing of the proposed approach have been successfully accomplished in MATLAB/Simulink. The results of the simulation reveal that along with the active power injection to the grid, the conditioner is capable to; pay compensation for harmonics, corrects sags and swells in voltage and also regulates the load voltage at its nominal value.
\end{abstract}

Keywords - Solar PV, Unified Power Quality Conditioner, Power Quality, Grid Integration.

\section{INTRODUCTION}

The demand for electric power in several developing countries, specifically in Pakistan, is growing gradually. Due to environmental and economic concerns, renewable energy resources have been emerging widely in order to meet this demand, among these resources, sunlight is the most abundant one. Useful electrical energy can be achieved from the luminous energy of the sun by making use of solar photovoltaic. The major advantages and characteristics of a solar photovoltaic system are: environment friendly energy without the emission of greenhouse gases, long-lasting operation, installation is effortless, operational cost is negligible, no moving or rotating components are entailed in generating power, and most importantly, the PV system is much cheaper than other renewable resources such as wind energy system and hydropower system. Middle class people cannot only recover some money as far as their electricity bills are concerned but can vend the excess power to the utility by supplying it back to the grid.

With the advances in modern power electronics, non-linear loads have been strongly grown on the distribution network. Moreover, the injection of a huge amount of harmonics in the electrical system can increase the system reactive power demand and hence, degrade the power quality. This low power quality can damage the equipment on the consumer side. This research gives energy consumers an opportunity to contribute in power generation and sell it. Thus, the system suggested in this work can contribute towards Pakistan's power sector by making use of solar energy for refining the power quality as well as active power injection to the grid.

This paper is structured as Section II provides an overview about the background of the research, Section III presents a general description of the proposed system, Section IV describes the system in detail, whereas, Section V analyzes the process of simulation and presents an overview of the results, and the last section i.e. Section VI portrays the conclusion of this research article.

\section{BACKGROUND}

Grid penetration of solar energy has been emerging since the development of modern power electronics [1]. However, integrating solar PV with grid is not a simple job because it may give rise to problems of power quality [2].

Power quality has become the principal concern for the realization of a smart grid [3]. Renewable energy resources such as wind and Solar PV behave intermittently. As far as weak distribution systems are concerned this behavior leads to power quality problems [4]. Few of the power quality issues, that may rise as a result of entrance of solar energy in the power network, are distortions in current and voltage waveforms, over-voltage (voltage swell) and voltage dip (sag), reactive power flow [3]-[9]. Such disturbances in voltage may also often initiate erroneous tripping and may damage the switching equipment. Capacitor banks heat up as a result of these disturbances [7], [10]. Likewise, non-linear loads are considerably growing on the consumer side. such a wide range 
usage of power electronics-based, non-linear loads cause the problems of power quality. As a result, the quality of power is becoming a concern for the utilities and also for the consumers. Such type of loads give rise to harmonics in current, which is the main cause of power quality issues. The current harmonics give rise to harmonics in system voltage. These power quality issues badly disturb the operation of the equipment connected to the power grid and can even cause damage to them. Due to these disturbances, transmission and distribution losses may also increase [11].

Several methods have been used to resolve the issues concerning power quality. Some of the frequently adopted methods to refine the quality of power are power filters, passive or active or their mutual combination which is named as hybrid filters. Active Power Filters (APFs) have two basic configurations based on their connection i.e. shunt or series APF, Active power filters can be used together with passive filters and such combination is termed as Hybrid filters. Another possible combination is of series and shunt APFs which is known as Unified Power Quality Conditioner (UPQC), distribution static compensator and static Volt Ampere Reactive Compensator (VAR compensator).

In this work an effort is made to inspect a technique for the grid connection of solar PV that is also capable of mitigating the issues of power quality. UPQC has proven to be effective in removing both the current and voltage distortions [11]. In UPQC the voltage and current disturbances are handled by the series and shunt APFs, respectively. PV array is connected in between the two APFs (at the DC link) to deliver the power necessary for compensating the power quality problems and the extra power is supplied back to the distribution station. A recent research uses a UPQC for the same purpose. The UPQC proposed in [1] is fed by a solar PV array. However, the system is limited only to harmonics compensation and problems like voltage sag and swell are not tackled.

\section{PROPOSED SYSTEM}

The overall layout of the proposed UPQC is illustrated in Figure 1. This study uses a single-phase system. A simple and easy control strategy is employed to control the series APF. The phase angle of the voltage from the grid side is obtained by means of a Phase Locked Loop (PLL). While, the nominal value of RMS voltage of the grid is used in generating the load reference voltage. The controller effectively monitors the operation of the series APF to compensate for the issues linked with grid voltage.

A single-phase Synchronous Reference Frame (SRF) technique is used to design controller for the shunt APF. The controller effectively monitors the operation of shunt APF to remove harmonics in current and avoid their entrance back into the grid.

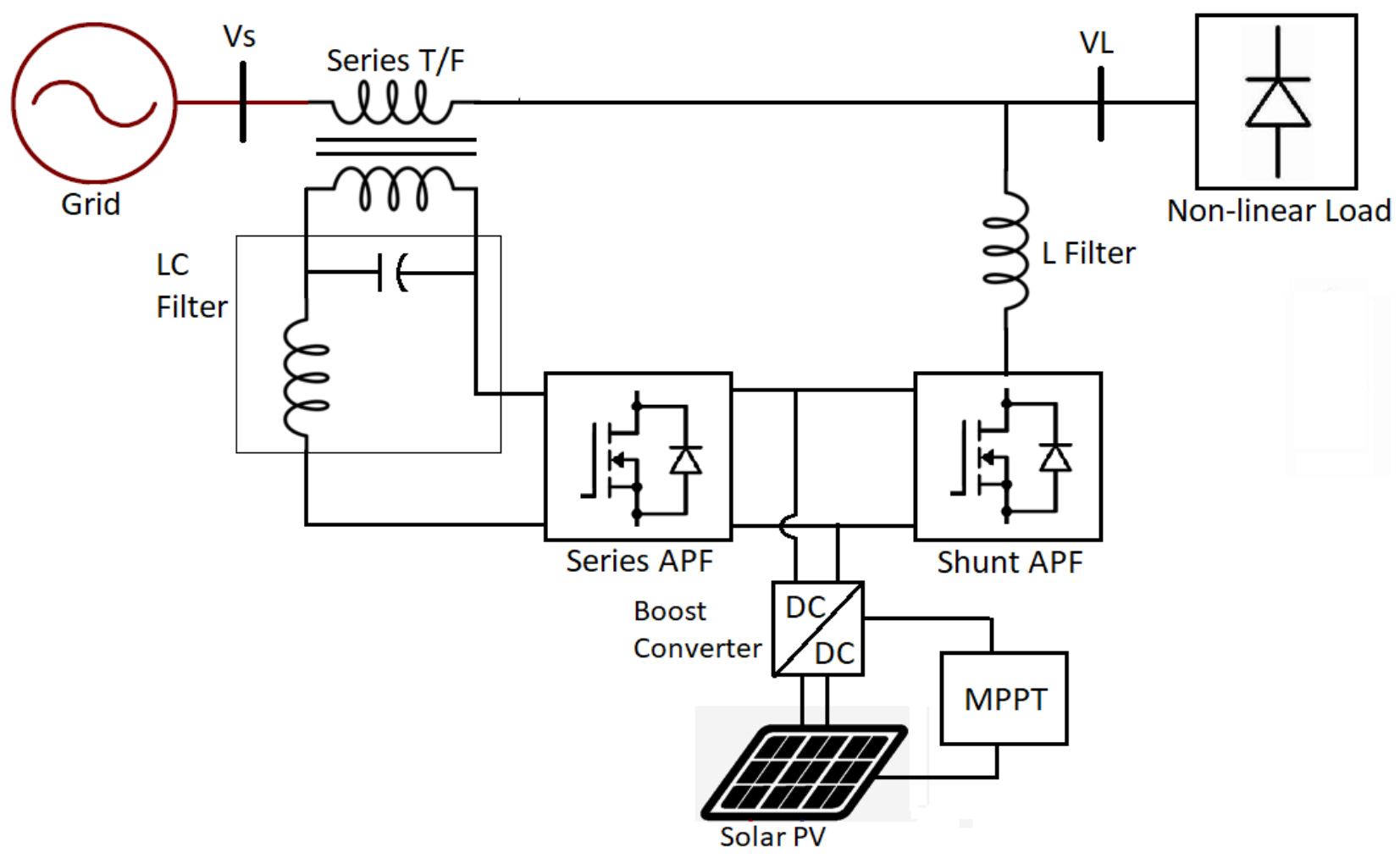

Figure 1. Layout of the Overall System 


\section{System DescriPTION}

This section describes the significant parts of the system under study. Implementation and simulation of the system has been accomplished in Simulink/MATLAB. The process of simulation has been depicted in Figure 2. Each subsystem is described in the following subsections.

\section{A. Solar PV Subsystem}

The Simulink arrangement of the solar PV subsystem can be viewed in Figure 3. Each part of this subsystem is described below.

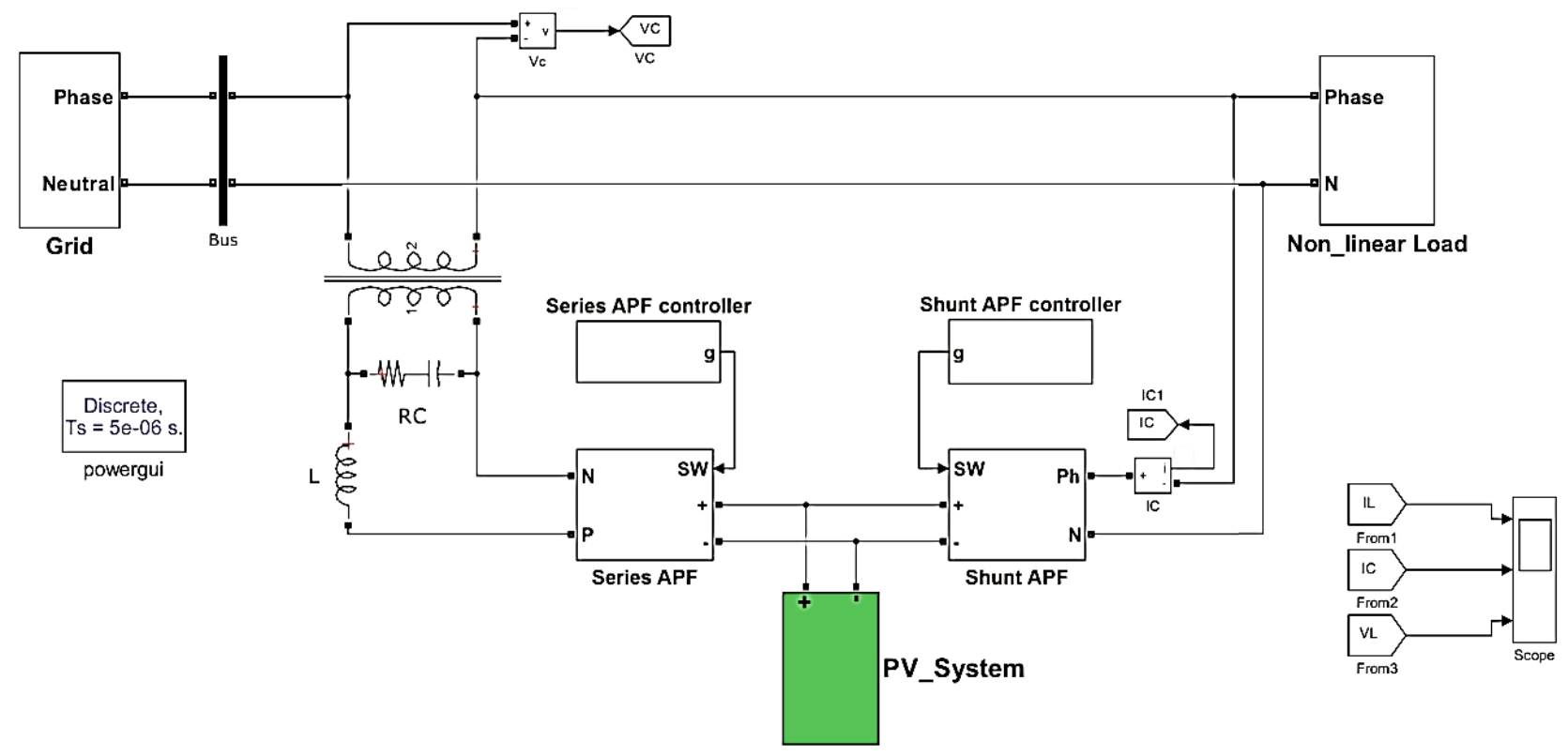

Figure 2. Simulink Diagram of the Proposed System

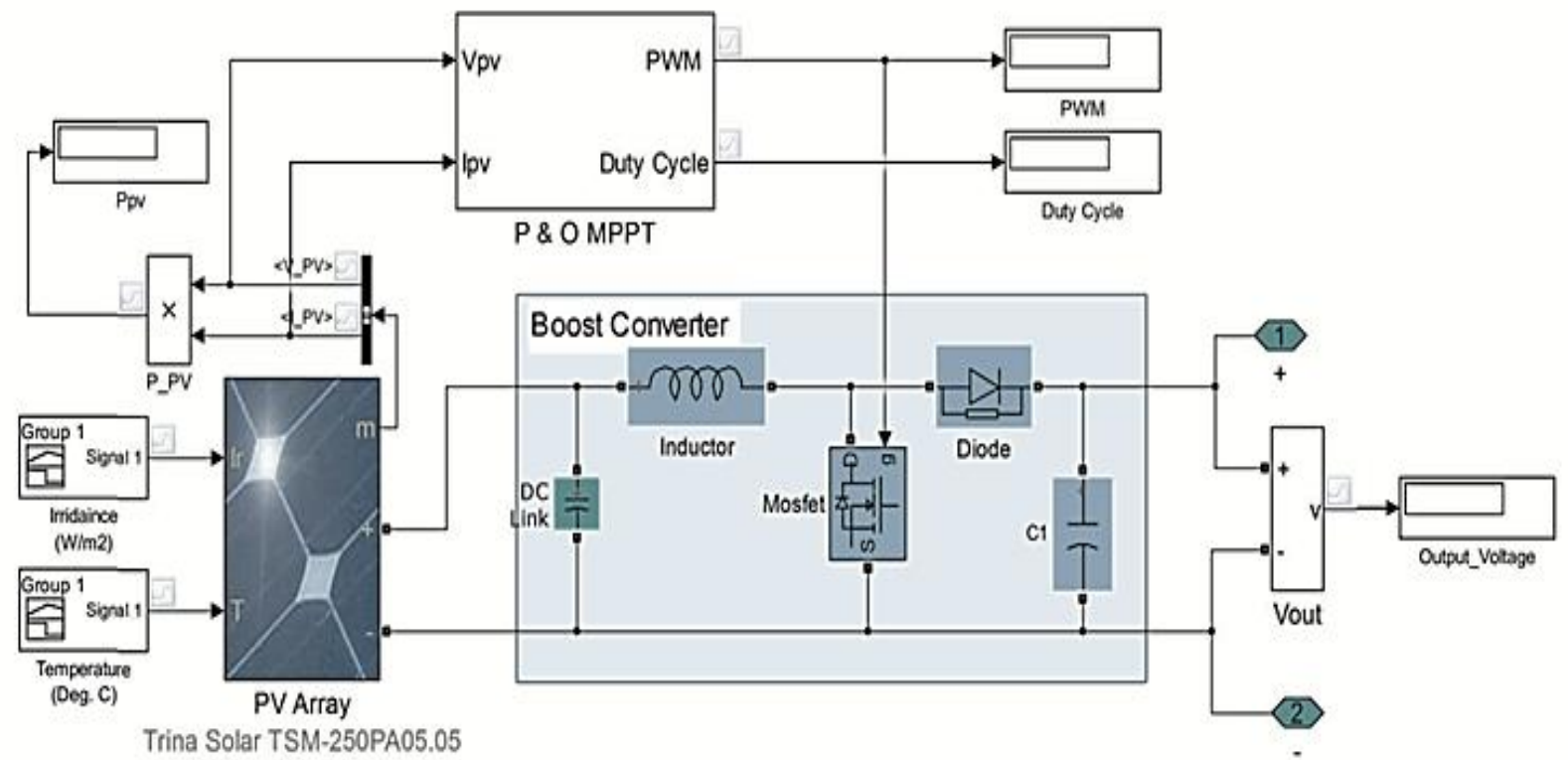

Figure 3. Simulink Diagram of the Solar PV Subsystem 


\section{1) Solar PV Array Block}

A negligible amount of power is produced individually by each cell of the module. Therefore, for applications that require high power, PV cells are connected in series and parallel configurations to form module. Panels are made up of these modules. Similarly, to configure the PV array for the desired output power, a number of panels are connected together using series and parallel connections.

The PV array block of the proposed system contains 8 parallel strings each with 10 modules tied in series. The PV array has a maximum power of $20 \mathrm{KW}$. The solar PV array of the system is based on mathematical equivalent model of a PV cell with single diode. Figure 4 shows a Thevenin-based equivalent circuit of a single diode cell.

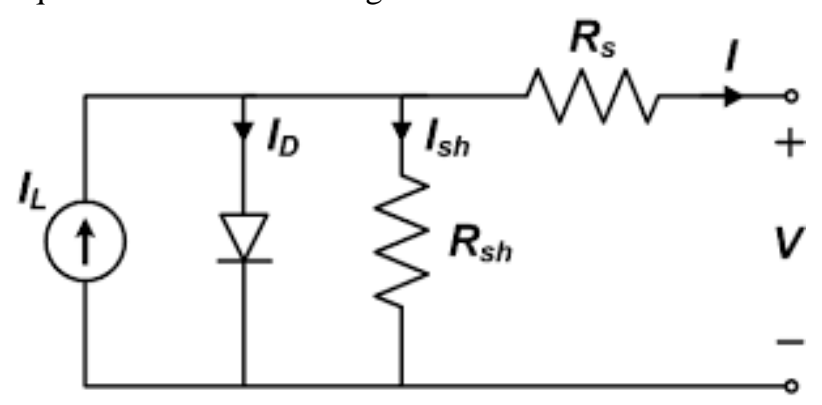

Figure 4. Thevenin-based Equivalent Circuit of PV Cell

The single diode model comprises of a diode connected across a photon current source $\left(\mathrm{I}_{\mathrm{L}}\right)$, shunt resistance $R_{s h}$, and series resistance $R_{s}$. Trina Solar TSM-250PA05.05 (datasheet is given in Table I) has chosen for the proposed system. This block takes two input signals i.e. irradiance $\left(\mathrm{W} / \mathrm{m}^{2}\right)$ and temperature $\left({ }^{\circ} \mathrm{C}\right)$.

TABLE I. SPECIFICATIONS OF THE PV MODULE

\begin{tabular}{|l|l|}
\hline Quantity & Value \\
\hline $\mathrm{R}_{\mathrm{S}}$ (Series resistance) & $0.2351 \Omega$ \\
\hline $\mathrm{R}_{\mathrm{SH}}$ (Parallel resistance) & $286.8727 \Omega$ \\
\hline $\mathrm{I}_{\mathrm{sc}}$ (short circuit) & $8.55 \mathrm{~A}$ \\
\hline $\mathrm{V}_{\text {oc }}$ (open circuit) & $37.4 \mathrm{~V}$ \\
\hline P max & $249.86 \mathrm{~W}$ \\
\hline $\mathrm{V}_{\mathrm{MPP}}$ (MPP Voltage) & $31 \mathrm{~V}$ \\
\hline $\mathrm{I}_{\text {MPP }}$ (MPP Current) & $8.06 \mathrm{~A}$ \\
\hline Diode ideality factor (a) & 0.96295 \\
\hline I photovoltaic & $8.5728 \mathrm{~A}$ \\
\hline I leakage & $9.6463 \times 10^{-11} \mathrm{~A}$ \\
\hline
\end{tabular}

\section{2) Boost Converter}

The PV array is coupled with a supercapacitor that helps to minimize the variations in the PV output. The supercapacitor is then coupled with a step-up boost converter. This converter always has its output voltage more than its input voltage for all the values of the duty ratio. A Pulse Width Modulation (PWM) signal is produced that operates the Metal Oxide Semiconductor Field Effect Transistor (MOSFET) based Switch. The converter intends to increase the voltage and maintain the Maximum Power Point (MPP) operation of the PV array.

The MPP is tracked through a proper MPP Tracking (MPPT) algorithm by fine-tuning of the duty cycle of the switching signal. The optimal working of the converter requires the input resistance to be equal to the optimal resistance [12] i.e. to fulfill the condition for maximum power transfer [13].

Eq (1) and Eq (2) are used for estimating the parameters of the converter, inductor and capacitor respectively.

$$
\begin{aligned}
& L_{c}=\frac{D(1-D)^{2} R}{2 f} \\
& C_{c}=\frac{D}{R\left(^{\Delta V_{o} / V_{o}}\right) f}
\end{aligned}
$$

Estimated parameters of the boost converter can be viewed in Table II.

TABLE II. ESTIMATEd PARAMETERS OF BOOST CONVERTER

\begin{tabular}{|l|l|}
\hline Parameter & Value \\
\hline Switching Frequency & $10 \mathrm{KHz}$ \\
\hline Inductor & $30 \mathrm{uH}$ \\
\hline Capacitor & $10 \mathrm{mF}$ \\
\hline Dc Link Capacitor & $5000 \mathrm{uF}$ \\
\hline
\end{tabular}

\section{3) Perturb and Observe MPPT Algorithm}

Various blocks from the Simulink library are used to create $\mathrm{P} \& \mathrm{O}$ MPPT algorithm. The Simulink diagram is given in Figure 5. In $\mathrm{P} \& \mathrm{O}$ scheme, the duty ratio in the beginning is either steped up or down from its initial predefined value and the path of process is maintained if the power moves up, otherwise, the path of process is changed [14].

\section{B. Shunt APF Control}

Current compensation is provided through proper generation of the compensating current. There are several techniques that can be adopted for this purpose. Here, a Synchronous Reference Frame (SRF) based controller is employed to obtain the reference signal. The current or voltage fundamental components are converted from stationary reference frame $(a b c)$ into a rotating reference frame $(d q$ synchronous) that rotates at a synchronous speed. The Simulink diagram of the single phase SRF-based control algorithm is given in Figure 6. The load current $I_{L}$ is chosen as actual fictitious component $I_{\alpha}$ and the component $I_{\beta}$ is obtained through a phase delay of $\pi / 2$ radians, see Equation 3 .

$$
\left[\begin{array}{l}
I_{\alpha} \\
I_{\beta}
\end{array}\right]=\left[\begin{array}{c}
I_{L}(\theta) \\
I_{L}(\theta-\pi / 2)
\end{array}\right]
$$

Once, the dual-phase rotating reference frame $d q$ has been obtained from the dual-phase stationary reference frame, the direct component of current, Id is then obtained using 
Equation 4. The line voltage angle is extracted by means of a PLL (Phase Locked Loop) and the DC component of current, $I d_{D C}$ is extracted using a low pass filter (second-order). The shunt APF also regulates the DC bus voltage by making use a PI controller. Difference of the actual DC link voltage and a preset reference is obtained and is given to a PI controller to achieve $I_{d c}$. This control signal also signifies the over-all active power transmitted from the PV to the DC bus. This signal along with regulation of the DC link voltage also recompenses for the losses. Equation 5[15] is implemented to obtain the sinusoidal reference current for the shunt APF.

$$
\begin{aligned}
& i d=i_{\alpha} \cdot \cos \theta+i_{\beta} \cdot \sin \theta \\
& i_{s}^{*}=\left(I d_{D C}+I_{d c}\right) \cos \theta
\end{aligned}
$$

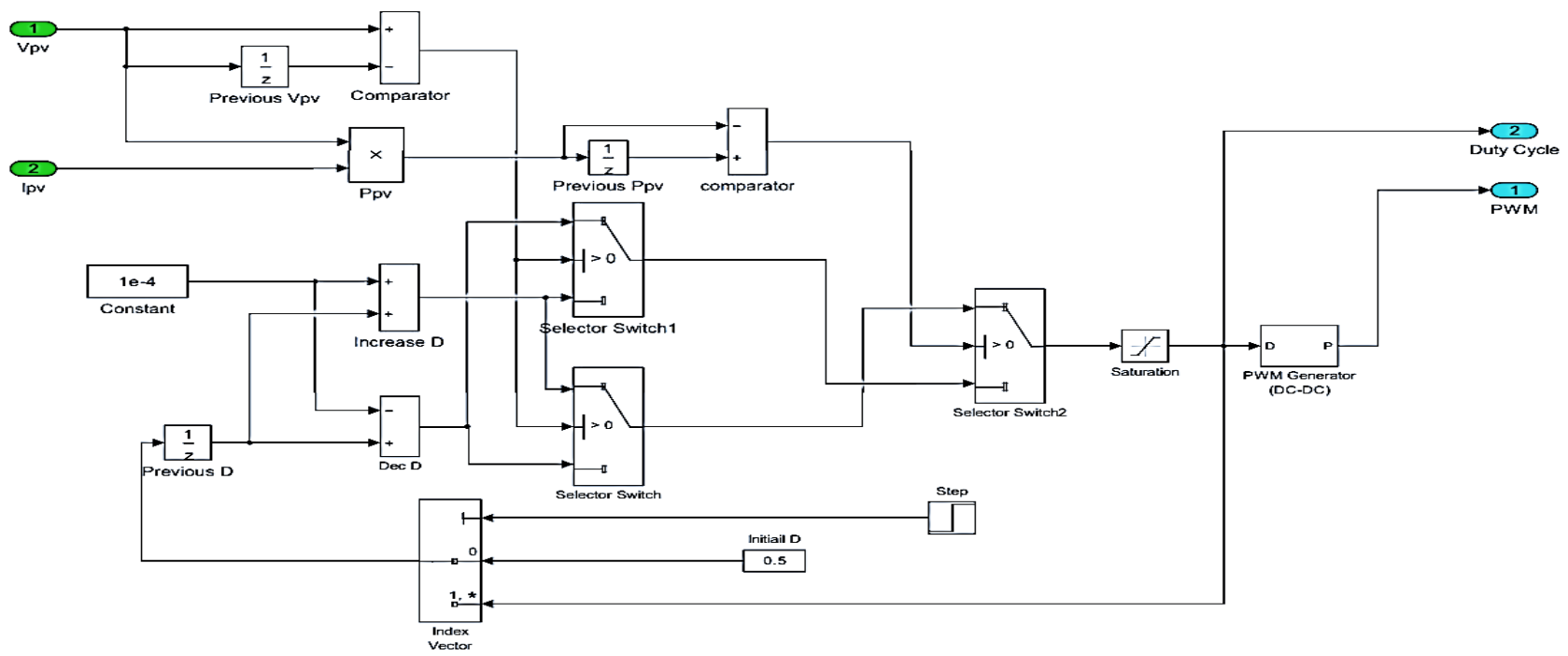

Figure 5. Simulink Diagram of P \& O MPPT

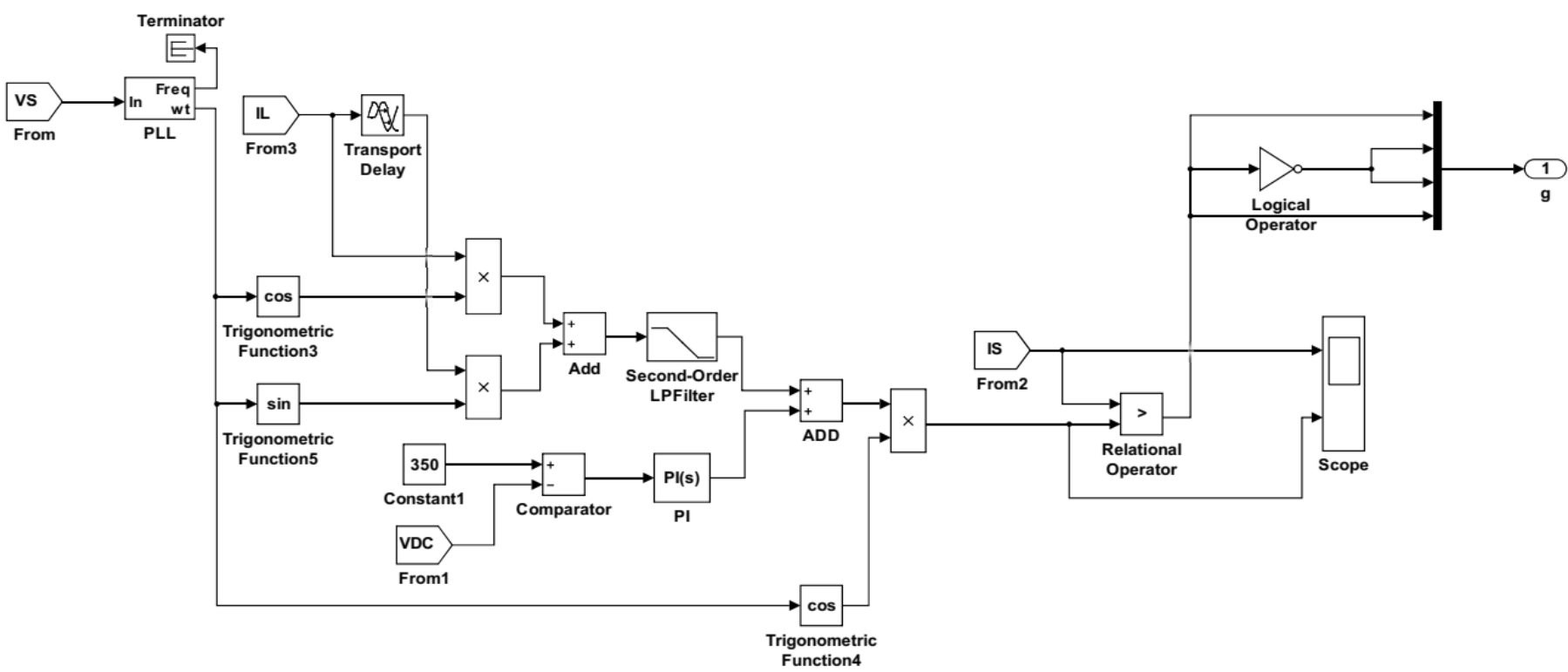

Figure 6. Simulink Diagram for the Control Signal Generation for Shunt APF 


\section{Series APF Control}

This control strategy generates a reference load voltage and compares it to the actual load voltage to get rid of the line voltage distortions. Thus, there is no distortions in the load voltage. The Simulink model of this control strategy is given in Figure 7. The angle of the line voltage is determined by making use of a Phase-Locked Loop (PLL) is acquired to determine the angle of the line voltage and then by using sine function the quadrature unit vector $\sin w t$ is produced. Then the desired value of amplitude is multiplied with the sinusoidal waveform and in this way the reference load voltage signal is generated. Finally, the actual voltage across the load and the reference load voltage are compared. The output of the comparator is then fed to a hysteresis band controller to generates a switching signal that operates the inverter (Series APF) switches.

\section{Utility Grid}

This simulation uses a controlled voltage source as a grid to properly apply the voltage-related issues to the system. Harmonics in voltage waveform and voltage sag and swell can be produced through the grid model to check this system under these disturbances. The nominal grid voltage is taken as $230 \mathrm{~V}$ (RMS) under normal operating conditions.

\section{E. Non-Linear Load}

Model of the non-linear load is made up of of a full bridge rectifier. The output of the bridge rectifier is coupled to a resistor. Simulink schematic of the non-linear load is given in Figure 8.

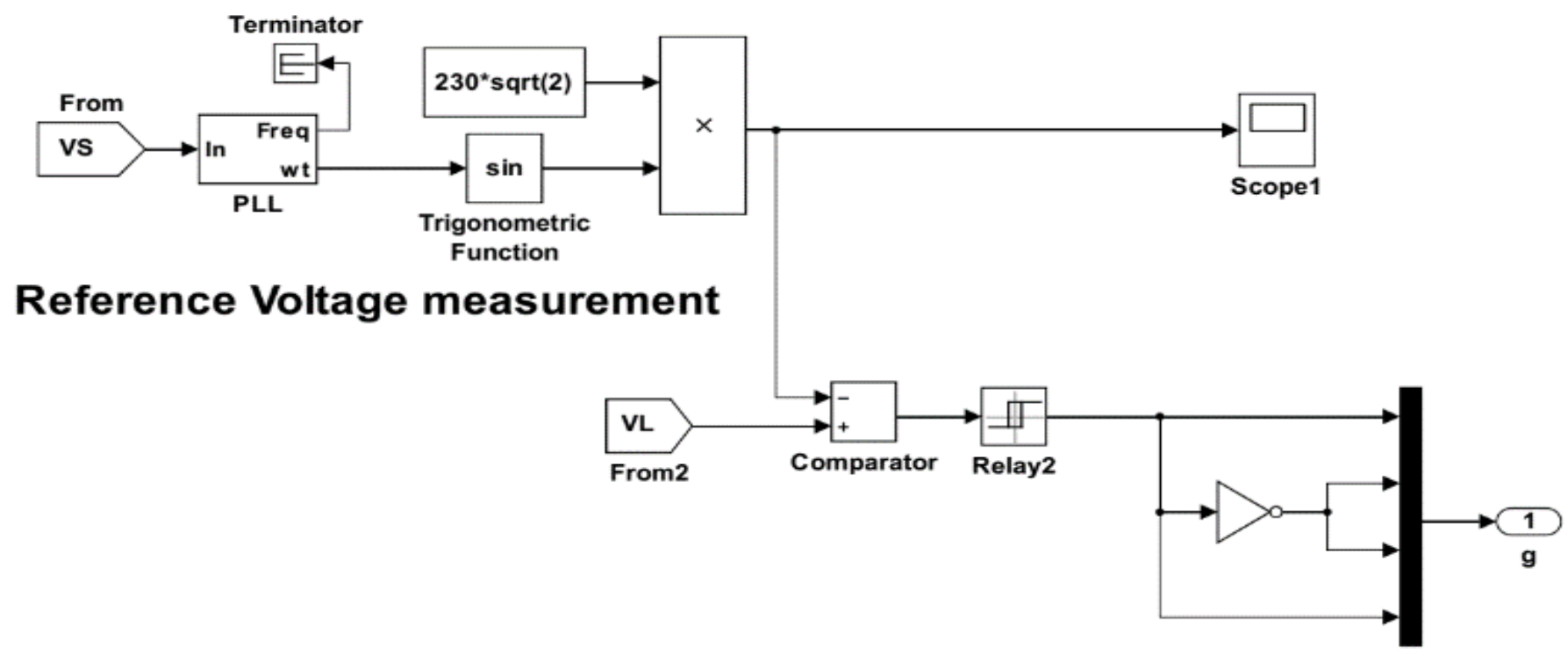

Figure 7. Control Diagram for Series APF

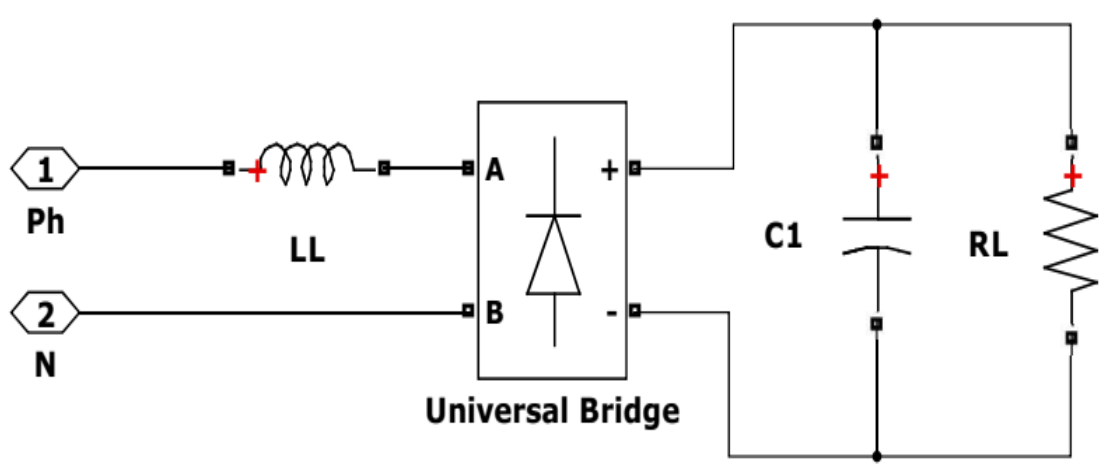

Figure 8. Simulink Diagram of non-linear load 


\section{SIMULATIONS \& RESULTS}

The model has been simulated by applying different power quality disturbances and the following cases have been considered.

\section{A. The Load Current Harmonics}

The performance of the aproach is analyzed under distorted load current. The waveforms of the distorted load current, shunt APF supplied current and the supply current are shown in Figure 9. THDs (Total Harmonic Distortions) for both the load and supply currents are presented in figures 10 and 11 respectively. Total Harmonic Distortion (THD) of the load current is $104.7 \%$. Waveform and THD of the load current confirm that the load current is entirely distorted by the non-linear load. THD of the supply current is $2.57 \%$. Waveform of the supply current and its THD confirm that the harmonics are successfully blocked from flowing back into the grid. Waveform of the current supplied by the Shunt APF verifies that the current generated by PV go back into the grid, along with the necessary compensation.

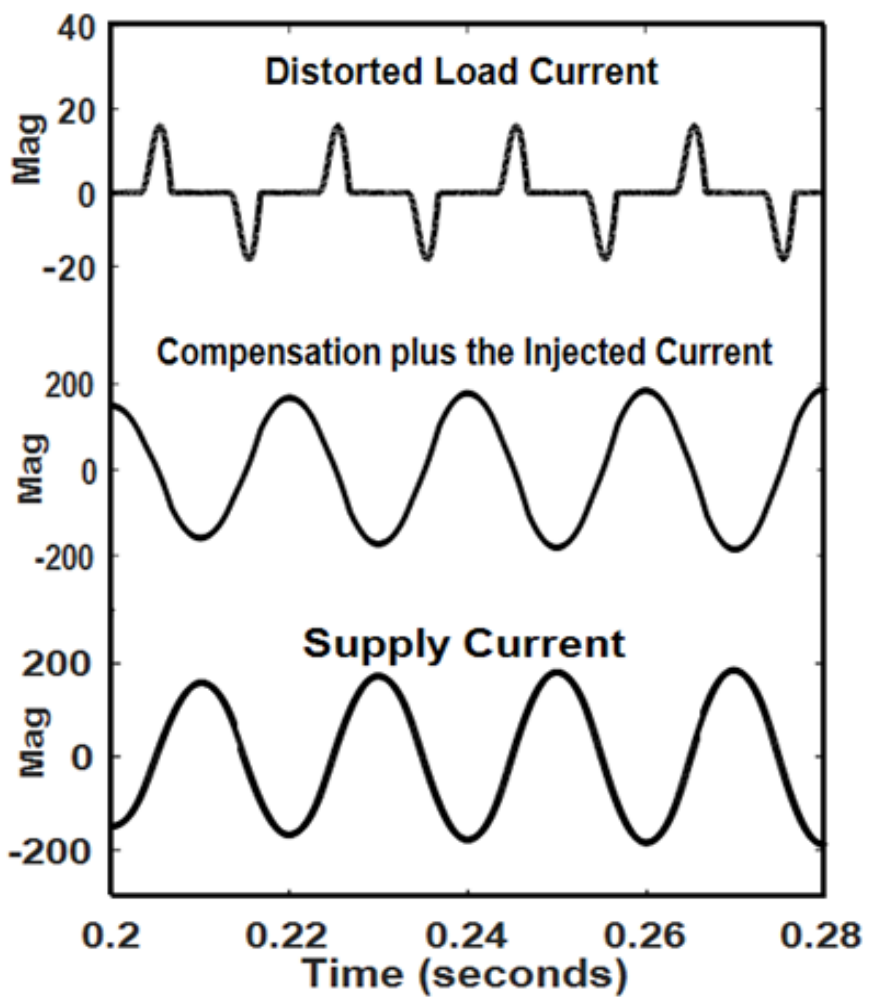

Figure 9. Current Harmonics

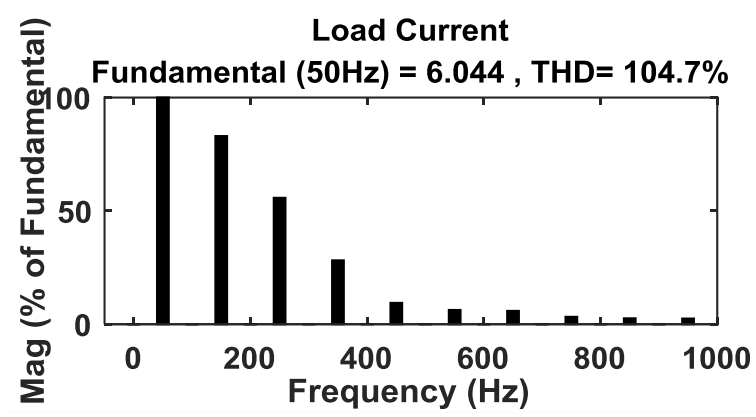

Figure 10. Total Harmonic Distortion

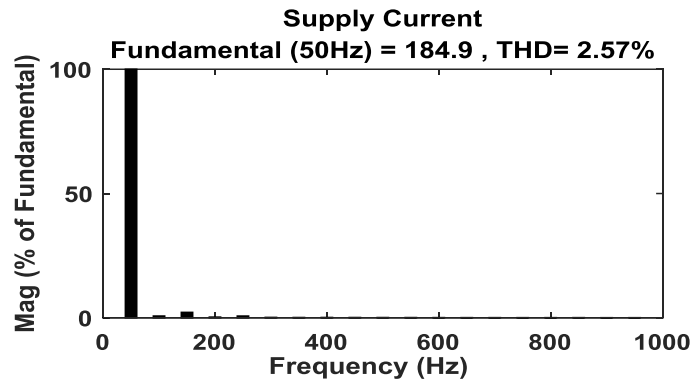

Figure 11. Supply Current THD

\section{B. Voltage Swell}

The system is analyzed under voltage swell fault at the supply side. Waveforms of the grid voltage, voltage provided by the series APF and load voltage can be seen in Figure 11. The diagram shows that the required compensation voltage is generated by the series APF and there is no voltage swell on the load side. Thus, the voltage across the load is maintained at the nominal RMS voltage of the grid voltage. Consequently, the sensitive loads are protected against the voltage swell.

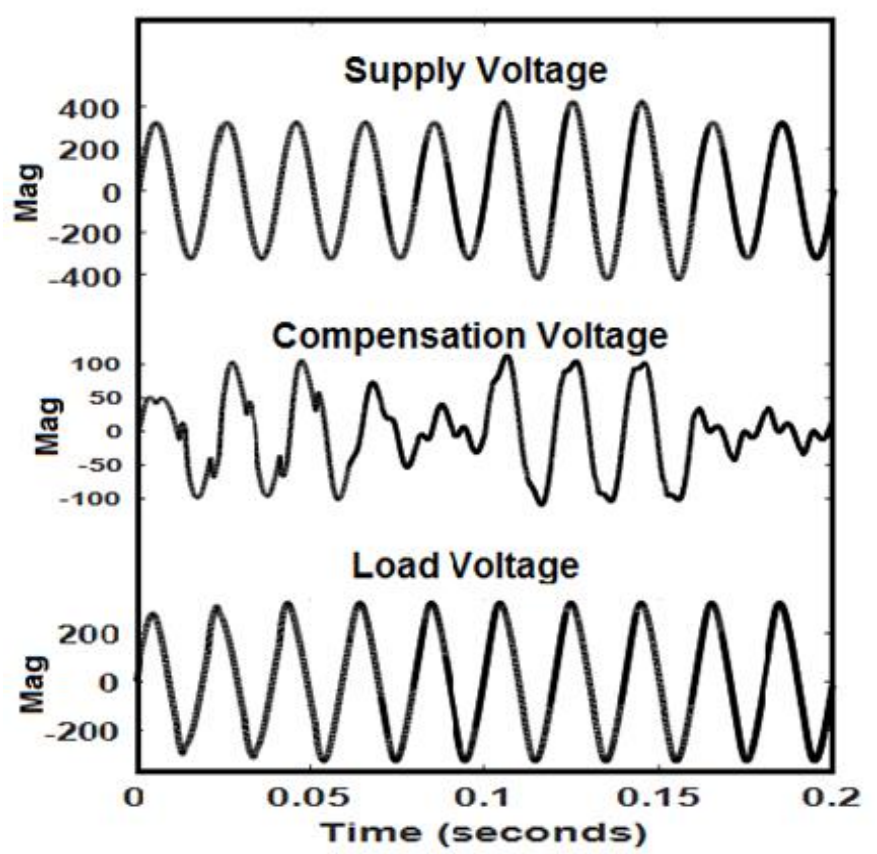

Figure 12. Voltage Swell 


\section{Voltage Sag}

A voltage dip from the grid side is introduced into the system. The line voltage, load voltage and compensation voltage are shown in Figure 13. Waveform of the load voltage shows that there is no voltage sag on the load side. So, the series APF effectively created the necessary compensation to retain the load voltage at the estimated RMS value.

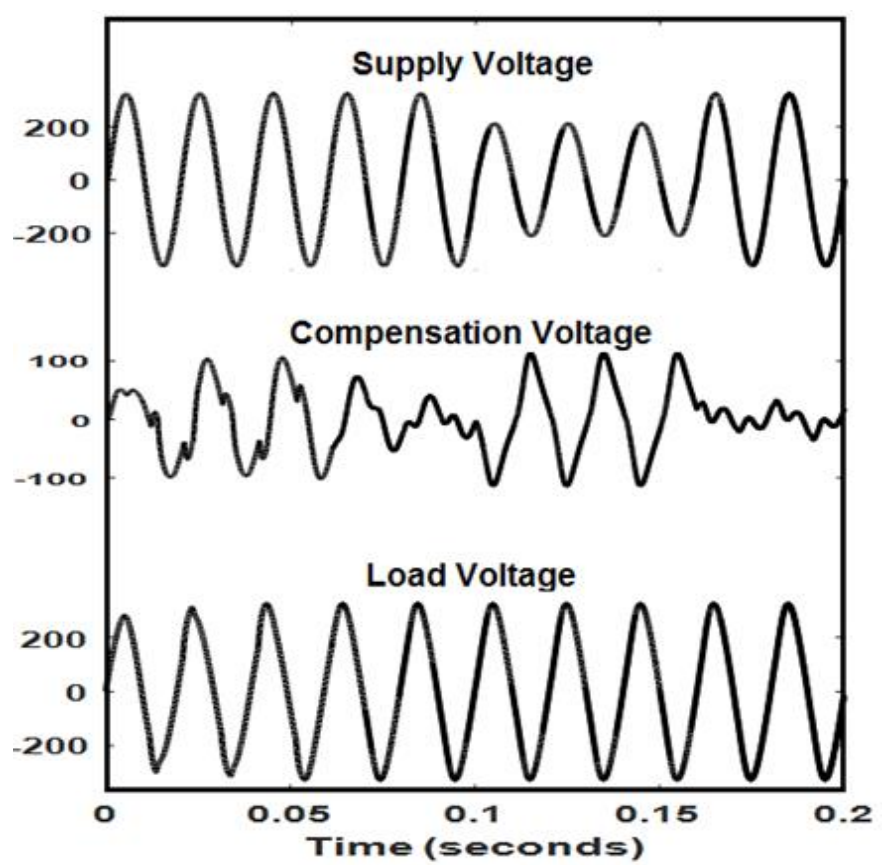

Figure 13. Voltage Sag

\section{Supply Voltage Harmonics}

The supply voltage is distorted by introducing third, fifth and seventh harmonics. waveforms for different voltages are given in figure 14.

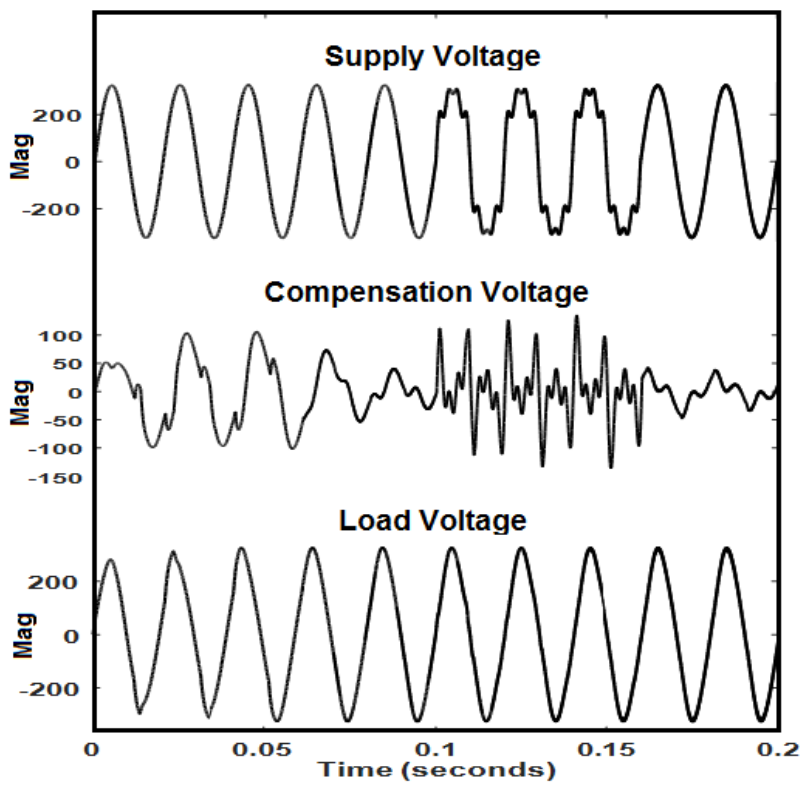

Figure 14. Voltage Harmonics
The grid and load voltage THDs are displayed in figures 15 and 16 respectively. The THD of the load voltage is $4.94 \%$ and that of the supply voltage is $21.32 \%$. It is clear from the waveforms and THD values that the harmonics of the supply have been overcome and protection of sensitive load has been improved.

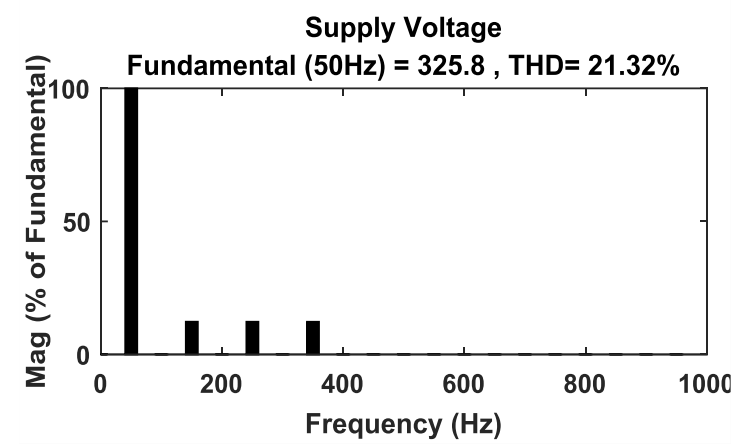

Figure 15. Supply Voltage THD

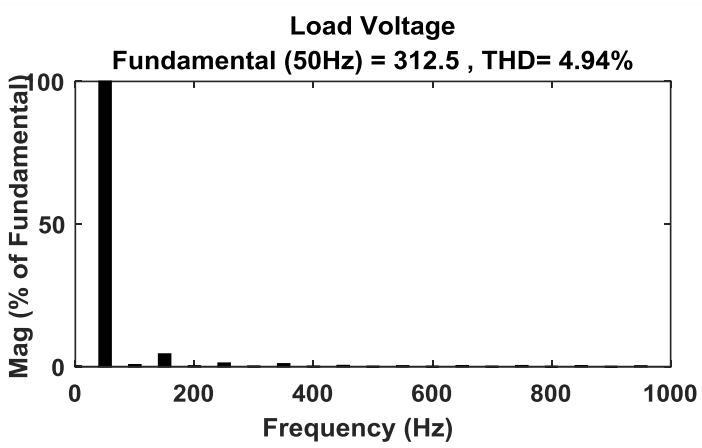

Figure 16. Load Voltage THD

\section{CONCLUSION}

A UPQC with PV array at its DC link was implemented and simulated in Simulink/MATLAB. The system was properly explained and the results were thoroughly analyzed. Proper control techniques for the Series and Shunt APFs were implemented to solve the voltage and current related distortions, respectively. An SRF control method was employed for the shunt APF. The compensation current provided by this APF of the system was proved to be successful in removing the current harmonics. This APF was also responsible to send the active power of the PV array to the grid and also maintain the voltage across the DC link at a predefined reference.

PV system with a boost converter was used in the DC link of the UPQC. The MPP operation was ensured using the Perturb and Observe MPPT method.

The system was observed under harmonics in load current and supply voltage. THDs of the voltage and current waveforms were obtained on both the load side and supply sides. The load current THD decreased from $104.7 \%$ to $2.57 \%$. In other words, a $97.54 \%$ reduction in load current THD was attained. Similarly, THD of the supply voltage was decreased from $21.32 \%$ to $4.94 \%$ at the load side i.e. a reduction of $76.83 \%$ supply voltage THD was attained. Thus, 
the THD values observed in simulation verify that the current harmonics were successfully blocked from entering back into the grid and voltage harmonics were blocked to keep the voltage sensitive loads safe. Supply voltage sag and swell faults were also corrected appropriately by the conditioner. In addition to the specified functionality, the PV array active power was successfully exported to the grid by the conditioner.

\section{ACKNOWLEDGMENT}

We are glad to show gratitude to our supervisor, Prof. Dr. Naeem Arbab, who is one of the most experienced Professors in the University of Engineering and Technology, for his supervision and directions. Moreover, we want to acknowledge the department of US-PCASE for financially supporting us throughout the course of this research. We are also extremely grateful to the officials of KP Directorate of Science \& Technology for facilitating this research work.

\section{REFERENCES}

[1] Yahia Bouzelata, Erol Kurt, Rachid Chenni, Necmi Altın, Design and simulation of a unified power quality conditioner fed by solar energy, International Journal of Hydrogen Energy, Volume 40, Issue 44, 26 November 2015, Pages 15267-15277, ISSN 0360-3199.

[2] Akagi H, Watanabe EH and Aredes M. Instantaneous power theory and applications to power conditioning. Wiley-IEEE Press, April 2007, New Jersey, USA.

[3] Patel, Ashish, Hitesh Datt Mathur, and Surekha Bhanot. "A new SRF- based power angle control method for UPQC- DG to integrate solar PV into grid." International Transactions on Electrical Energy Systems 29.1 (2019): e2667.

[4] X. Liang, "Emerging Power Quality Challenges Due to Integration of Renewable Energy Sources," in IEEE Transactions on Industry Applications, vol. 53, no. 2, pp. 855-866, March-April 2017. doi: 10.1109/TIA.2016.2626253.

[5] Farhoodnea, Masoud, et al. "Power quality impact of grid-connected photovoltaic generation system in distribution networks." Research and Development (SCOReD), 2012 IEEE Student Conference on. IEEE, 2012.

[6] Renders, Bert, et al. "Profits of power-quality improvement by residential distributed generation." 2007 42nd International Universities Power Engineering Conference. IEEE, 2007.

[7] Devassy, Sachin, and Bhim Singh. "Design and performance analysis of three-phase solar PV integrated UPQC." IEEE Transactions on Industry Applications 54.1 (2017): 73-81.

[8] E. Yao, P. Samadi, V. W. S. Wong, and R. Schober, "Residential demand

side management under high penetration of rooftop photovoltaic units," IEEE Transactions on Smart Grid, vol. 7, no. 3, pp. 1597-1608, May 2016.

[9] A. Parchure, S. J. Tyler, M. A. Peskin, K. Rahimi, R. P. Broadwater, and M. Dilek, "Investigating pv generation induced voltage volatility for customers sharing a distribution service transformer," IEEE Trans. Ind. Appl., vol. 53, no. 1, pp. 71-79, Jan 2017.

[10] Singh, A. Chandra and K. A. Haddad, Power Quality: Problems and Mitigation Techniques. London: Wiley, 2015.

[11] Mahela, Om Prakash, and Abdul Gafoor Shaik. "Comprehensive overview of grid interfaced solar photovoltaic systems." Renewable and Sustainable Energy Reviews 68 (2017): 316-332.

[12] Kumar, Ajay, Nitin Gupta, and Vikas Gupta. "A Comprehensive Review on Grid-Tied Solar Photovoltaic System." Journal of Green Engineering 7.1 (2017): 213-254.
[13] Garg, Akash, R. Saida Nayak, and Susma Gupta. "Comparison of P \& O and Fuzzy Logic Controller in MPPT for Photovoltaic (PV) Applications by Using MATLAB/Simulink." IOSR Journal of Electrical and Electronics Engineering (IOSR-JEEE) 4 (2015).

[14] M. A. G. de Brito, L. P. Sampaio, L. Galotto Jr., C. A. Canesin, "Evaluation of the Main MPPT Techniques for Photovoltaic Applications," IEEE Transactions on Industrial Electronics, vol. 60, no.3, pp. 1156-1167, March 2013.

[15] Da Silva, Sérgio A. Oliveira, et al. "Single-phase grid-connected photovoltaic system with active power line conditioning." Power Electronics Journal 20.1 (2015): 8-18.

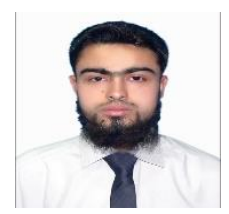

Niaz Ali has received his B.Sc Electrical Engineering degree from the University of Engineering and Technology Peshawar, Pakistan in 2014. He is currently pursuing his M.Sc Electrical Energy System Engineering from US Pakistan Center for Advanced Studies in Energy, University of Engineering and Technology Peshawar, Pakistan. His major research interests include Solar PhotoVoltaic (PV), MPPT techniques for Solar Photovoltaic, DC-DC converters, Active Power Filters (APFs) and Unified Power Quality Conditioners (UPQCs). Picture is attached.

Professor Dr. Muhammad Naeem Arbab is a Professor in University of Engineering and Technology Peshawar in Electrical Department. He got his Ph.D. from UK and is an author of two engineering books i.e., High Voltage Engineering and Electrical Power Generation and published more than 25 research papers.

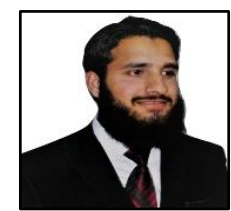

Rizwan Kamal has received B.Sc Electrical Engineering degree from department of Electrical Engineering University of Engineering and Technology Peshawar, Pakistan in 2014. He is currently pursuing M.Sc degree in Electrical Energy Systems Engineering from United States Pakistan Center for Advanced Studies in Energy (USPCAS-E) at University of Engineering and Technology Peshawar. He worked on first hybrid renewable energy system of Pakistana which is consist of solar PV, Micro-hydro and Biomass resources installed at Sakhakot, Malakand division KP, Pakistan.

Muhammad Bilal has received his Master's in Electrical Energy System Engineering from from United States Pakistan Center for Advanced Studies in Energy (USPCAS-E) at University of Engineering and Technology Peshawar in 2019. He worked as a research scholar at Power system Lab of Arizona State University U.S.A in 2016. Currently he is working as Assistant Manager in an R \& D Department of public sector industry, Pakistan. He is also doing a project on Grid connected 5MW Solar project for that industry with increased efficiency. His major research is in snart micro-grid architecture, control and economic dispatch problems. 